\title{
Study of Freshwater Prawn Diversity from Different Rivers of Jammu, India
}

\author{
Nidhi Slathia and Seema Langer \\ Department of Zoology, University of Jammu, Jammu-180 006, India \\ E-mail: nidhi1slathia@gmail.com
}

\begin{abstract}
Diversity of freshwater prawns and biological indices were studied from June, 2019 to May, 2020 in five rivers of Jammu region of J\&K. In total, five species of prawns belonging to Macrobrachium and Caridina genus were recorded. Out of the five species, Macrobrachium dayanum was dominant species present in all the surveyed water bodies whereas M. lamarrei was only in two water bodies. The different diversity indices showed significant differences. The highest and lowest values of Shanon-Weiner index, Margalef richness index and Pielou eveness index (\%) were 1.39 (Chadwal stream) and 0.67 (Sai stream), 0.79 (Chadwal stream) and 0.30 (Sai stream), 0.97 (Sai stream) and 0.80 (Chadwal stream). Sai stream showed least diversity and abundance of species compared to other study sites, which is also revealed by the results of cluster analysis that showed this site to be significantly different indicating it to be the least suitable habitat.
\end{abstract}

Keywords: Diversity indices, Prawn diversity, Macrobrachium, Caridina, Shanon-Weiner index, Margalef richness index, Pielou eveness

Conservation of aquatic biodiversity especially freshwater diversity is one of the important matters of concern as it is exhausting at an accelerated rate due to various factors like human activity, loss of habitat, over harvesting, increasing pollution levels, competition from exotic species and other biotic and abiotic components. Freshwater is essential for life and yet it comprises of only $3 \%$ of total water present on earth (Souilmi and Tahraoui 2021). Freshwater ecosystem includes lakes, rivers, wetlands and these harbour remarkable life diversity and serve as home to $10 \%$ of total species (Strayer and Dudgeon 2010). Decapoda is the most significant order that includes enormous diversity of freshwater crustaceans. Among decapoda crustaceans, caridean shrimp and prawns represent second largest group after Brachyura (Davis et al 2018) and about 800 species living in fresh water have been described from this infraorder (De Grave et al 2015). Freshwater prawns form economically important group as most of them are harvested from the wild or cultured for food as well as aquarium trade. Overall diversity of freshwater prawns is rapidly declining or under risk category mainly due to competition from invasive species, change in climate and commercial developmental projects (De Grave et al 2015). Freshwater prawns play a crucial role in the recycling of nutrients, structuring and functioning of the ecosystem (Snyder, 2016) and form one of the most dominant biomass rich group in the river ecosystem (Greathouse and Pringle 2006). Being keystone species in the river ecosystem, they actively participate in sustaining the food web by transferring nutrients and energy from decay matter and producers to higher trophic levels and also play an important role as scavengers (Camara et al 2009). Quality of water and anthropogenic pollution can be determined by presence of species and their abundance (Sharma and Chowdhary 2012, Susilo et al 2020).

Jammu region is bestowed with large number of perennial rivers which form part of Indus river system. The most important rivers that flow in the Jammu region are Ravi and Chenab that harbour abundant fishery resources. Since freshwater fauna especially prawn resources are at risk of being carried away from their respective habitats (Ranganu and Marippan 2011), therefore it is necessary to have a reliable data based on surveys and identification of prawns from natural habitats. These records are prerequisite for further biological studies related to cultural aspects and protection of the fauna.

\section{MATERIAL AND METHODS}

Sampling sites, duration and method: The present research was carried out in five rivers (Fig. 1). Gho Manhasa River (Site 1), Chakrali River (Site 2), Chadwal River (Site 3), Sai River (Site 4) and Nagri river (Site 5). Gho Manhasa, Chakrali and Sai rivers form the tributaries of Chenab whereas Chadwal and Nagri form the tributaries of Ravi. Gho Manhasa, Chakrali and Sai rivers lie in district Jammu with an elevation of 300,302 and 333mrespectively whereas Chadwal and Nagri rivers lie in Kathua district with an elevation of $379 \mathrm{~m}$ and $318 \mathrm{~m}$ respectively. Bottoms of Gho Manhasa and Chakrali rivers comprise mostly of cobbles, Sai 
and Nagri rivers is mostly sandy whereas the Chadwal river had mostly sandy bottoms with few large stones at the marginal area around the river. Plenty of aquatic vegetation is found along the margins of Gho Manhasa, Chakraliand Nagri rivers, moderate vegetation was observed in the marginal area of Chadwal along with floating macrophytes in the middle of the river and Sai River had scanty vegetation. The study was conducted for a period of one year i.e., from June, 2019 to May, 2020. Sampling was done early in the morning between 7 to 9 am with the help of cast net having mesh size $5 \mathrm{~mm} \times 5 \mathrm{~mm}$. The collected samples were counted on the spot and were brought to the Department of Zoology, University of Jammu in ice cooled boxes.

Identification of the specimens: The identification of the prawn specimens was done following Paul (1991), Cai and $\mathrm{Ng}$ (2002), Sharma and Subba (2005) and Thomas (2011). The prawns belonging to genus Macrobrachium were larger in size whereas those belonging to genus Caridina were smaller in size, therefore they were studied under stereomicroscope. Shape of the rostrum, number of teeth present on dorsal and ventral side of rostrum, characteristics of second pereiopod, shape of telson and arrangement of spines on dorsal and distal end of telson form important features for identification.

Diversity analysis

Relative abundance of prawn species were determined by the following formula

$$
\text { R.A. }=\frac{\text { Number of specimens of a species }}{\text { Total number of specimens of all the species }} \times 100
$$

Diversity index among different sites was calculated using Shanon Weiner index

$$
H=-\Sigma\left(\frac{n i}{N}\right) \log 2\left(\frac{n i}{N}\right)
$$

Where, $\mathrm{ni}$ is the total count of all the specimens of a species, total count of all the specimens of all the species.

Species richness was calculated using Margalef index

$\mathrm{M}=\mathrm{S}-1 / \ln \mathrm{N}$, where $\mathrm{N}$ is the total number of specimen, $\mathrm{S}$ is the number of species.

Evenness was calculated using Pielou index

$\mathrm{J}=\mathrm{H} / \mathrm{In} \mathrm{S}$, where $\mathrm{H}$ is the Shannon Weiner diversity index, $\mathrm{S}$ is the total number of species in the sample

Statistical analysis and Hierarchical cluster analysis was performed using PAST software (Version 4.03) and Microsoft Excel 2016

\section{RESULTS AND DISCUSSION}

Morphological identification of the specimen showed the presence of five species of prawn from the five water bodies of Jammu region. All the specimens were identified upto the species level except one species which was identified only upto the genus level and named as Caridina spp. The species belong to two genera i.e., Macrobrachium and Caridina and the species include Macrobrachium dayanum, Macrobrachium kistnense, Macrobrachium lamarrei, Caridina babaulti, Caridina spp. (Fig.1).

Macrobrachium dayanum: The rostrum of this species is elongated reaching upto or beyond the length of the antennal scale. It may be curved or slightly curved upwards. Chela of second pereiopod is longer than the carpus, which is moderately longer than merus. Two pairs of spines are present on the dorsal surface of the telson. Uropod consists of accessory spine on the telson.

Macrobrachium kistnense: The length of the rostrum is short rarely reaching the length of antennal scale. The rostrum is deep and straight. Merus of second pereiopod is shorter than the carpus and ischium is shorter than chela, merus and carpus. Distal half of the telson bears two pairs of spines. Uropod does not have accessory spine.

Macrobrachium lamarrei: Length of the rostrum is long, reaching past the antennal scale. Distal end of rostrum is slender and turned upwards. The most important feature of this species is the wide edentulous gap between first two and third dorsal teeth. Chela of second pereiopod is shorter than merus but carpus is longer than merus. Telson possesses two pairs of dorsal spines and uropod does not have accessory spine.

Caridina babaulti: This species is recently discovered in this region. Rostrum of this species is long, reaching the third antennular segment of antennular peduncle. Distal end of the rostrum is straight with slight bend in the upward direction. Ischium of second pereiopod is half in length as merus and merus is almost equal to carpus. Distal end of telson has

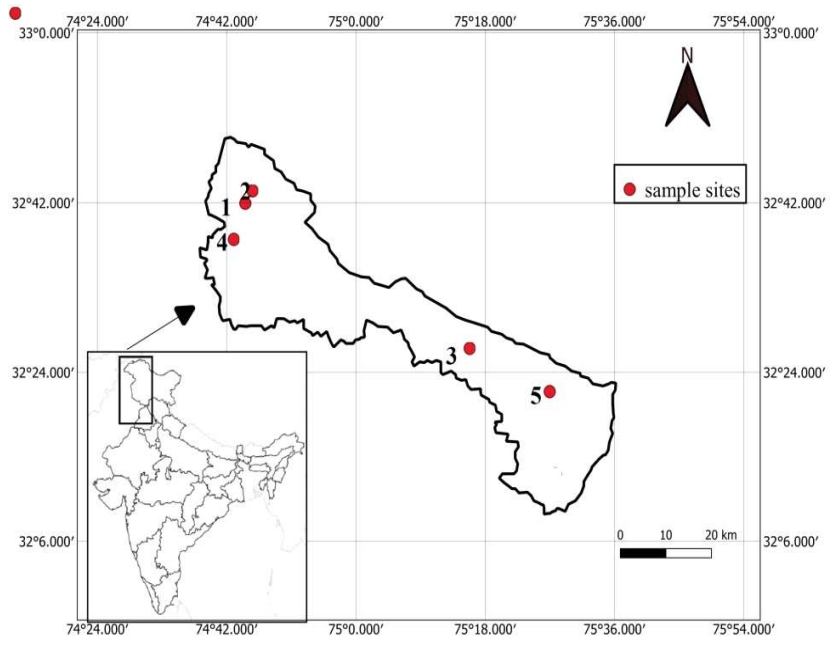

Fig. 1. Map showing different sampling sites 
convex shape and 5-6 pairs of teeth are present on dorsal surface

Relative abundance of species at different sites: Among all the species, $M$. dayanum occurred at all the stations showing its cosmopolitan distribution and its highest relative abundance was at station 2 (Table 1). Station 3 showed high relative abundance of $M$. kistnenseand $M$. lamarrei showed its high abundance at site 4. C. babaulti was found at station 3 and 5. Earlier only three species were recorded from five sites, Caridina species has been recently recorded from the study sites.

Cluster analysis between stations: Hierarchal cluster analysis using Euclidean distance method was performed to reveal the similarity between stations based on abundance

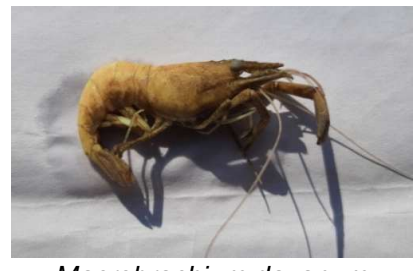

Macrobrachium dayanum

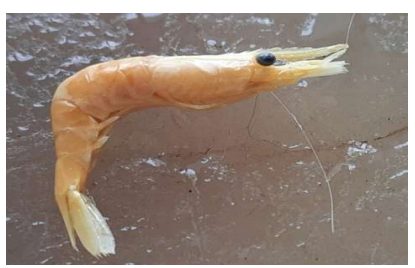

Macrobrachium lamarrei

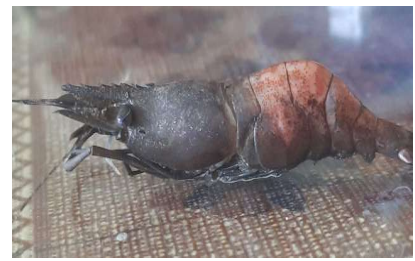

Macrobrachium kistnense

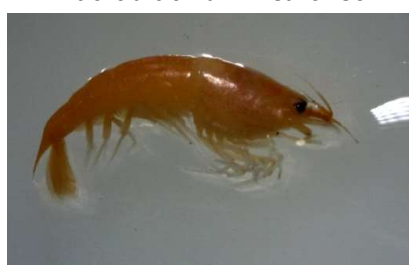

Caridina babaulti

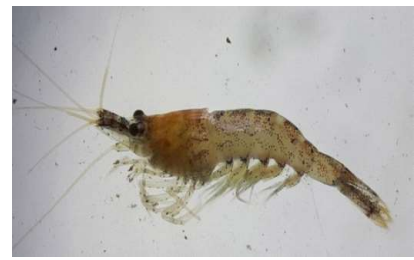

Caridina spp.

Fig. 2. Photographs of different species and presence/ absence of the species (Fig. 3). Site 1 and 2 are closely associated in first cluster whereas site 3 and 5 forms part of first cluster with slight distance. Site 4 is totally distinct than the other sites and forms second cluster.

Diversity indices: Shanon- Weiner diversity index indicated the highest diversity at station 3 and lowest diversity at station 4 (Table 2). Margalef richness index was highest at station 3 whereas low values were found to be at station 4 . Species evenness is described as the relative abundance of individuals of each species present in a community. Species evenness found no significant variations among stations and all the values were well within the range between $0.75<\mathrm{E}<1$

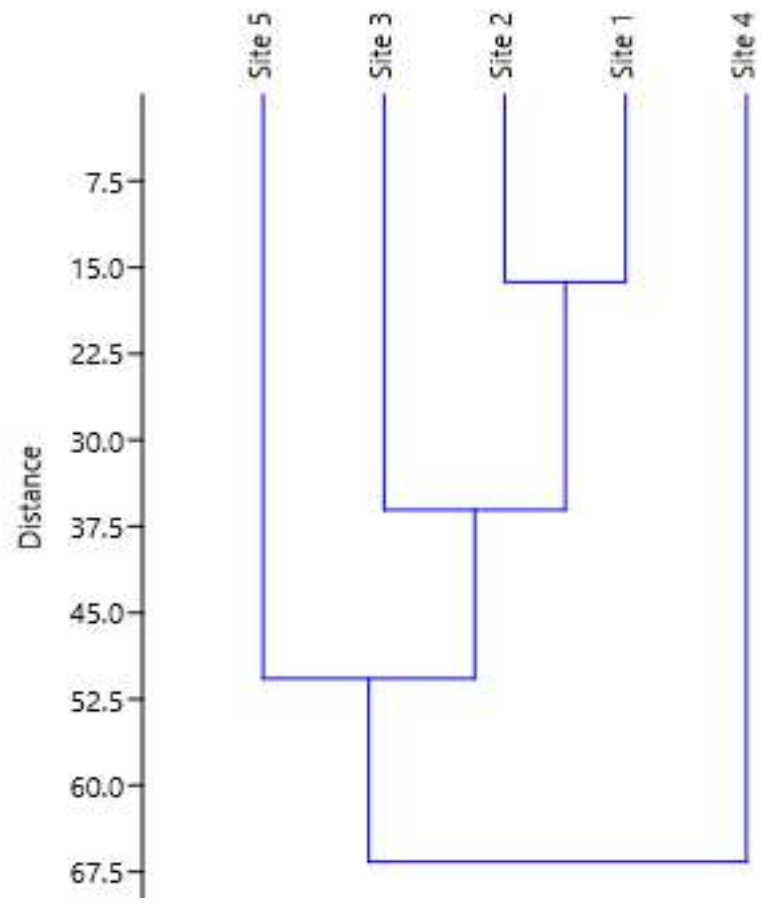

Fig. 3. Dendrogram of the sampling sites based on presence and abundance of the species

Table 1. Relative abundance of species at different sites

\begin{tabular}{|c|c|c|c|c|c|}
\hline Species & Site 1 & Site 2 & Site 3 & Site 4 & Site 5 \\
\hline M. dayanum & 50 & 38 & 69 & 11 & 78 \\
\hline M. kistnense & 25 & 16 & 38 & 0 & 65 \\
\hline M. lamarrei & 0 & 0 & 18 & 17 & 0 \\
\hline C. babaulti & 18 & 12 & 17 & 0 & 29 \\
\hline C. spp. & 17 & 15 & 12 & 0 & 19 \\
\hline
\end{tabular}

Table 2. Diversity indices at different sites

\begin{tabular}{lccccc}
\hline Index & Site 1 & Site 2 & Site 3 & Site 4 & Site5 \\
\hline Shannon Weiner index & 1.28 & 1.27 & 1.39 & 0.67 & 1.24 \\
Margalef index & 0.63 & 0.68 & 0.79 & 0.30 & 0.57 \\
Pielou index & 0.89 & 0.89 & 0.80 & 0.97 & 0.87 \\
\hline
\end{tabular}


which represents stable community (Kreb 1989). Diversity indices showed that site 3 followed by site 1 and 2 are most preferred habitats as it shows highest number and diversity of prawn species. It may be due to abundant food resources present in these sites like benthic organisms, algae and planktons. Prawns feed on benthic organisms and are detritivores (Sharma and Subba 2005), therefore there is significant positive correlation between its abundance and food resources as indicated by Bakhtiyar (2008). These streams have abundant aquatic vegetation, which may have provided the species with ample space, so no significant competition among species occurred. Low diversity and low rate of abundance of species was observed at site 4 , indicating loss of its suitability for sustaining life due to destruction of natural habitats, increased level of pollution and over exploitation of the species. Macrobrachium siwalikense was earlier reported from station 4 (Nipoon 2015) but during the present survey, no specimens of $M$. siwalikense were found revealing that the population of this species must have wiped out. Jewel et al. (2018) observed similar reasons for declined diversity and low abundance in one of the studied habitats.

\section{CONCLUSION}

The results of the present study will serve as baseline information regarding fresh water prawn diversity in Jammu region. Diversity and abundance of prawn species is affected by the anthropogenic factors that has significant effect on them. The study suggests that site 4 needs appropriate management and conservation strategies to prevent the further loss of populations from this site.

\section{REFERENCES}

Bakhtiyar Y, 2008. Food preferences of Macrobrachium dayanum (Henderson) and Labeo rohita (Hamilton) and nutritional status and culture of food organisms. Ph.D. Dissertation, University of Jammu, Jammu, India.

Cai $\mathrm{Y}$ and $\mathrm{Ng}$ PKL 2002. The freshwater palaemonid prawns (Crustacea: Decapoda: Caridea) of Myanmar. Hydrobiologia 487: 59-83.

Camara IA, Konan MK, Diaman D, Edia G and Gourence EO 2009. Ecology and diversity of freshwater shrimps in Banco National Park, Côte d'Ivoire (Banco River Basin) Knowledge and Management of Aquatic Ecosystem 393: 05.
Davis KE, De Grave S, Delmer C and Wills MA 2018. Freshwater transitions and symbioses shaped the evolution and extant diversity of caridean shrimps. Communications Biology 1: 16.

De Grave S, Smith KG, Adeler NA, Allen DJ, Alvarez F, Anker A, Cai Y, Carrizo SF, Klotz W, Mantelatto FL, Page TJ, Shy JY and Villalobos JL 2015. Dead Shrimp Blues: A global assessment of extinction risk in freshwater shrimps (Crustacea: Decapoda: Caridea). PLoS ONE 10: e0120198.

Greathouse EA and Pringle CM 2006. Does the river continuums concept applies on a tropical island? Longitudinal variation in a Puerto Rico stream. Canadian Journal of Fisheries and aquatic Sciences 63: 124-1152.

Jewel MAS, Haque MA, Khatun R and Rahman MS 2018. A comparative study of fish assemblage and diversity indices in two different aquatic habitats in Bangladesh: Lakhandaha Wetland and Atari River. Jordan Journal of Biological Sciences 11: 427-434.

Krebs CHJ 1989. Ecological methodology. University of British Columbia, Harper Collins Publisher, p 645.

Paul AL 1991. Distribution, ecology and biology of fresh water prawns (Macrobrachium spp.) of North Eastern region. Ph.D. Dissertation, North- Eastern Hill University, Shillong, India.

Ranjanee S S and Marippan N 2011. A genetical and ecological diversity of fresh water Prawns Macrobrachium canarae and Caridina gracilirostris from Kanyakumari Dist., Tamil Nadu, India. International Journal of Genetic Engineering and Biotechnology 2: 23-32.

Sharma N 2015. Taxonomy and population dynamics of freshwater prawns inhabiting some Jammu waters. M. Phil Dissertation, University of Jammu, Jammu, India.

Sharma KK and Choudhary S 2012. Diversity of Molluscan fauna inhabited by River Chenab-fed Stream (Gho-Manhasan). Indian Journal of Ecology 39(1): 48-51.

Sharma S and Subba BR 2005. General biology of freshwater prawn, Macrobrachium lamarrei $(\mathrm{H}$. Milne-Edwards) of Biratnagar, Nepal. OurNature 3: 31-41.

Snyder MN, Freeman MC, Purucker ST and Pringle CM 2016. Using occupancy modeling and logistic regression to assess the distribution of shrimp species in lowland streams, Costa Rica: Does regional groundwater create favorable habitat. Freshwater Science 35(1): 80-90.

Souilmi F and Tahraoui S 2021. Assessment of spatial and seasonal water quality variation of the upstream and downstream of Oum Er-rabia River in Morocco. Indian Journal of Ecology 48(1): 4751.

Strayer DL and Dudgeon D 2010. Freshwater biodiversity conservation: Recent progress and future challenges. Journal of the North American Benthological Society 29: 344-358.

Susilo VE, Suratno and Fadillah N, Narulita E and Wowor D 2020. Diversity of freshwater shrimp (decapoda) from bandealit rivers Meru Betiri National Park, East Java, Indonesia.Journal of Physics: Conference Series1465 012009.

Thomas T 2011. Freshwater shrimps of the family Atyidae de Haan of Kerala and culture of a selected species for forage/food in aquaculture. Ph.D. Dissertation, Mahatma Gandhi University, Kerala, India. 